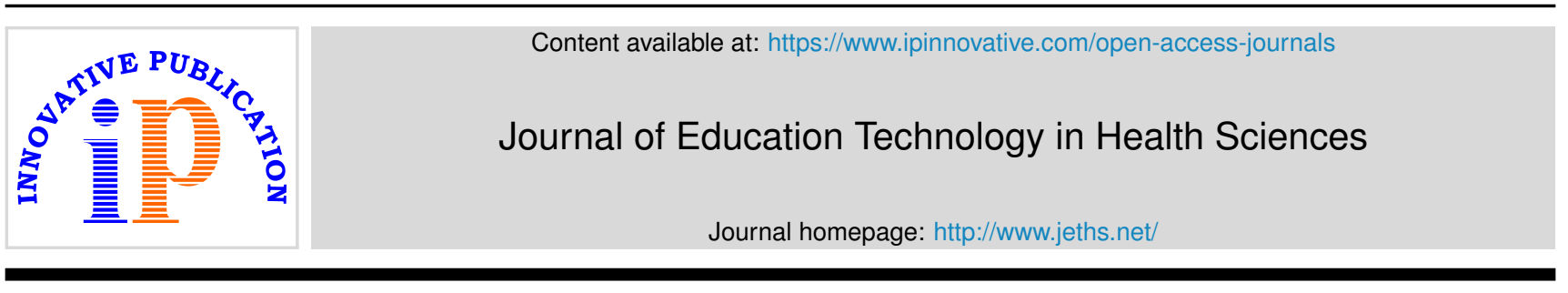

\title{
Conceptual Review
}

\section{Peer learning in health sciences-exploring pedagogy}

\author{
Swati Paranjape ${ }^{1, *}$, Madhavi Dharankar ${ }^{2}$ \\ ${ }^{1}$ Dept. of Physiotherapy, Seth G S Medical College, KEM Hospital, Mumbai, Maharashtra, India \\ ${ }^{2}$ Dept. of Educational Technology, SNDT Women's University, Mumbai, Maharashtra, India
}

\section{A R T I C L E I N F O}

\section{Article history:}

Received 07-04-2021

Accepted 25-04-2021

Available online 17-05-2021

\section{Keywords:}

Peer-learning

Pedagogy

Learning to learn

Student-centric

\begin{abstract}
A B S T R A C T
Learning is a social experience. In most of the health science disciplines students learn in variety of environments like clinical placements, laboratory and lecture-based setting. Peer learning can be a component in any of these environments. However, effectiveness of peer learning on learning outcomes is not extensively researched as like other formal instructional strategies. Present paper aims to discuss the conceptual understanding, theoretical basis and possible effects of peer learning on aspects of learning outcomes. This can offer the background information to design the future research on peer learning instructional strategy. Peer learning is beneficial pedagogical learning strategy which has all round effect on the process of learning. Cognitive benefits and outcomes on the learning as well as psychosocial outcomes like behaviour, critical reasoning, motivation, and appreciation of team work are also noted. However, scarcity and diversity in the research on peer learning makes it difficult to ascertain its benefits or shortcomings in terms of measurability and generalizability. Inclusion of peer learning as student centric, flexible and individualised approach can complement the individual needs of the learners. Comprehensive understanding of peer learning process, improved study designs considering the factors affecting group dynamics, and more representative sampling techniques can help overcome the barriers and can result in better understanding of this approach in health science education.
\end{abstract}

(C) This is an open access article distributed under the terms of the Creative Commons Attribution License (https://creativecommons.org/licenses/by/4.0/) which permits unrestricted use, distribution, and reproduction in any medium, provided the original author and source are credited.

\section{Introduction}

Learning is a social experience. In most of the health science disciplines students learn from variety of environments such as clinical placements, laboratory and lecture-based settings. Students, learn from their own experiences, by interacting with the other fellow students or senior students and also by observations. Availability of the technology, social networking web 2 tools, for exchanging ideas and sharing knowledge has enhanced the opportunities to the students to go beyond curriculum. It was found that the undergraduate medical students extensively use 'Facebook groups' to seek advice from peers on study related issues or exam preparation. ${ }^{1}$ Learners integrate this information through their personal framework. All these

\footnotetext{
* Corresponding author.

E-mail address: swati.paranjape@kem.edu (S. Paranjape).
}

ways of learning, influence the learner's thought process, application, problem solving abilities and decision making, in real life situations. Peer learning can be a component of any of these environments e.g. when students help each other in clinical settings there occurs unintentional or incidental learning. ${ }^{2}$ Researchers have emphasized the fact that peer learning being a very small part of the curriculum, ascertaining its benefits in terms of measurability and generalizability is not possible. ${ }^{3}$ There is a need of understanding the peer learning process. In present paper we focus on understanding peer learning as a 'process'. We discuss the conceptual understanding, theoretical basis, possible effects and shortcomings of peer learning on aspects of learning outcomes. This can offer the background information to design the future research on the peer learning instructional strategy. 


\section{Origin and Theoretical Perspectives of Peer Learning}

Origin of peer learning can be found way back in $19^{\text {th }}$ century. The comprehensive concept of peer learning was introduced by Jean-Pol Martin in 1987. ${ }^{4}$ However, peer learning was introduced in 1951 at 'Free University of Berlin' in higher education. It is seen that students can learn best when they are in intellectually motivating and challenging environment. One of such environments could be peer learning. This can be explained on basis which is related to the pyramid of hierarchy of needs introduced by Abraham Maslow, which consists, from base to peak, of

1. Physiological needs

2. Safety/security

3. Social/love/belonging

4. Esteem/self-confidence

5. Being/growth through self-actualization and selftranscendences.

The act of successful learning, preparation and teaching of others contributes to items three through five which essentially moving towards personal growth. ${ }^{5}$ Vygotsky (1930) quoted 'the one, who does the talking, does the learning: students learn by teaching their peers'. Some researchers have put forth cognitive theories, like Piagetian theory of constructivism along with Vygotsky's theory as basis of peer learning. ${ }^{6}$ These theories can help describing specific techniques used in peer learning. Some researchers have identified peer learning as instructional model based on the constructivist's theory of collaborative and cooperative learning. ${ }^{7}$

\section{Historical Versus Contemporary Perspectives}

Historically peer learning was considered more as pedagogical strategy; however, things have begun to change. The digital era has totally changed the way of learning. Rather than knowing how to do what is important today is to know where to look for. Recently a new term was introduced as "Peeragogy" in 2013. They gave peer learning a new perspective where the paradigm shifted from pedagogy to andragogy.

In educational reforms the traditional teacher-led model was challenged and the experiential learning was introduced. It supported learning as active and constructive process. It was argued that digital era has exposed the limitations of learning theories. A broad term "paragogy" was introduced which they called as a set of principles to understand learning together and "peeragogy" is specific term about peers learning together and teaching each other. Pedagogy refers to "child being supervised" whereas andragogy necessitates the adult educator or facilitator to be a part of the process. However actually these two are two ends of spectrum, rather than opposite terms. In peer-based set up the role of teacher or facilitator is shared by all the participants.

1. Learners bring their own experiences, strengths and weaknesses.

2. Process goes through phases of forming, norming, storming and performing.

3. Group cohesiveness is important. It defines acceptable behavior and practices.

4. Group works more cyclic way than linear fashion.

5. Conflicts or chaos can lead to either productive or destructive outcome.

6. If one can't cope can feel depressed and frustrated.

7. Too much hierarchical control can make participants passive and too much autonomy can lead to ignorance, misconception and chaos. ${ }^{8}$

\section{Conceptual Understanding}

What is peer learning and who can be called as peer? When it was used first in 1951, peers were considered as the ones of same age and educational level. However, peer has been described as someone of same social standing. Peer group is of those at same status with whom one interacts. ${ }^{4}$ Whiteman (1988) classified peers as 'near-peers' i.e. tutors at more advanced level than tutee while 'co-peers' as partners at work deemed to be at same level. ${ }^{4}$ Peers have no power over each other by virtue of their position or responsibility. ${ }^{9}$ Thus, peer is the student at same or different academic or experience level and learning is acquisition of knowledge, understanding or skill through instruction or experience. ${ }^{2}$ Thus peer learning is described as

"Acquisition of knowledge and skill through active helping and supporting among status equals or matched companions. It involves people from similar social groupings who are not professional teachers helping each other to learn and learning themselves by so doing". ${ }^{3}$

Peer learning involves form of student interaction with their peers and is designed to aid process of learning. ${ }^{4}$ Peer learning is an example of active learning where students get engaged into meaningful learning through not only by complex authentic problems but also social interactions. ${ }^{7}$ This social component in learning is unique feature of peer learning. Usually, peer learning approaches are used for learning outcomes like

1. Academic achievement

2. Meta-cognitive outcome

3. Study skills outcome

4. Nonacademic outcome like motivation, retention, attrition and attendance. ${ }^{4}$

There are various ways in which the recruitment of the peers is done. Peers can be same level equal/unequal status, cross level equal/unequal status. As there are varied methods used for group formation and recruitment of peers, groups 
are structured in variety of ways where group members can assume different roles and can exchange the roles. The group dynamics is found to be affected by variety of factors which ultimately reflect the learning outcome.

1. Status congruence or consistency

2. Helping behavior

3. Self esteem

4. Recipients' reactions to help

5. Attributions by the recipient about help ${ }^{4}$

When groups are allocated randomly multiple factors interact and influence group dynamics. Factors like attitude or personality of the peer leader or group member, where a dominating person can take over the session. For a successful and productive outcome there needs trust, confidentiality and mutual respect among participants. ${ }^{10}$ Interpersonal dynamics, learning styles of individual learners play a crucial role in peer learning. The one who is more agreeable and open can embrace peer learning better. One needs to give up competitiveness and nurture sharing their own knowledge as well as appreciate uniqueness of others. $^{11}$

\section{Forms of Peer Learning and Related Terminologies}

Over the years peer learning has taken various forms like peer tutoring, peer mentoring, peer assessment and collaborative or cooperative learning. The understanding of definitions of peer learning, differences between various terminologies is necessary. Though these terms are used interchangeably they are different. 'Tutoring' is characterized by specific role taking as tutor and tutee, whereas 'mentoring' is more of one-to-one interaction from more experienced worker. Whereas cooperative learning is described as 'structuring positive interdependence', which often requires prior training or else it can result in 'blind leading the blind'. In cooperative learning teacher intervention is expected in setting the goals and also in measuring and evaluating the educational achievements. ${ }^{9}$ In collaborative learning open ended but focused task is set. Here activity may be set by teachers but means of achievements are left to learners. ${ }^{9}$ Collaborative learning is more about 'learning to learn'. One must remember that interaction with peers differs qualitatively than that with the professional teacher, which may have its own advantages and disadvantages. ${ }^{12}$

It is observed that initial trend of recruiting the "best students" as helpers is changing to same level as helped, so that both of them face equal cognitive challenges. ${ }^{13}$

\section{Benefits of Peer Learning}

Research suggests number of benefits to participants in co-operative learning environment. It can be in form of enhancing motivation, increasing academic performance and retention, creativity, appreciation of diversity, and community skill development. ${ }^{4}$

Students find peer learning as a "safe learning environment'. 2,10 Maybe due to emotional support of fellow learners, ${ }^{14}$ comfort level, and freedom of expression. Students feel peers provide non-threatening feedback. ${ }^{2}$

Importantly peer learning not only helps learning material in question but also helps to learn about learning. ${ }^{15}$ It helps improving study habits, communication skills and self-confidence. ${ }^{2}$ In peer learning learners learn through discussion and assimilation and not by rote. ${ }^{16}$ Peer discussions, brainstorming, conflicts and disagreements are termed as "Cognitive conflicts" which contributes to learning. ${ }^{10}$ Peer learning can give opportunity to a student to take responsibility of their own learning. 9 Absence of instructor can be beneficial as it encourages self-directed learning. It can encourage reflective practice, self-awareness and lifelong learning competency. Often teachers provide information to the learners however it deskills the learners from developing one crucial competency of learning from each other. When teacher provides information skill of getting accurate information is never learnt. What is important to be learnt is 'how to judge the accuracy of information we receive. ${ }^{9}$

\section{Shortcomings of Peer Learning}

Peer learning however can't replace the other instructor led approaches all together. As mentioned earlier the success of the peer learning entirely depends on the factors affecting the group dynamics. Being social individuals, many peers may not be willing to offer honest feedback to peers compromising on their social relationship. ${ }^{17}$ In competitive environment one may find idea of sharing one's knowledge with the others not very appealing. There could be inhibition whether one can really learn from peers. ${ }^{9}$ There could be conflict or apprehension about learning from peers than learning from experts in learner's mind. ${ }^{17}$ Students may find it lacking the details and can prefer learning from instructors rather than peers. ${ }^{2}$ The biggest concern raised against peer learning is quality of the learning. Peer tutors or peers are neither content expert nor professional teachers. ${ }^{17}$ So quality is questioned as they lack complete knowledge and credibility. ${ }^{15}$ There may not be regulation over the content, so there is possibility of incorrect information being conveyed or learnt. ${ }^{10}$ Students may not be able to pullback and read through situation like professional teacher. ${ }^{16}$

\section{Research Challenges and Pitfalls}

When it comes to research on peer learning, Topping (1996) have emphasized the need of quality in design and execution of research. As discussed earlier, group dynamics is crucial and it directly influences learning outcomes. Hence considering group dynamics and controlling the 
confounding factors is extremely essential. It was stressed that assessment in peer learning should be broadened including assessment of its impact on cognitive abilities and transferable skills. There was a concern raised on the generalizability of the research on peer learning. ${ }^{1}$ Due to the social nature of peer learning, in light of socio-cultural theory, learning and in context with which it takes place are inseparable. ${ }^{17}$ Therefore, results of the peer learning experiments in controlled settings can't be assumed to apply in complex learning settings.

In spite of the differences in the opinions among researchers over possible benefits and shortcomings about peer learning it can certainly be recommended as supplementary strategy to augment the benefits on learning outcomes which can complement the individual needs of the learner. There is also a need of extensive strategic research on peer learning.

\section{Conclusion}

The literature on peer learning ascertains the benefits of peer learning. The uniqueness of peer learning is in its social aspect, where it can teach critical reasoning, self-directed learning and nurture lifelong learning. Peer learning not only offers cognitive benefits but also psychosocial benefits.

Present system emphasizes on teaching more than learning. Still the teaching remains teacher centric as most form of teaching occurs in form of classroom lectures. There needs shift the paradigm to student centric, individualized, problem based and flexible teaching programmes. Each student's approach to learning differs, which may differ not only from other student but also from the teachers' perspective. Understanding of learners' process of learning rather than teachers' teaching techniques is need of an hour. Peer learning can prove a good adjunct to fill this gap. Peer Learning strategy is still underutilized may be due to its shortcomings, especially about the generalizability of the research findings in actual real-life scenarios. However, the answer to that is full proof research strategies needed to be adopted. As this paper highlights inclusion and consideration of factors and their interaction in group dynamics is crucial in designing future research. Quality of learning is also often questioned where teacher intervention to certain extent can control the quality of content being delivered or conveyed. However, when the objective fulfilment is left on the learners, it encourages selfconfidence, decision making and most importantly learning how to learn. Potentials of this relatively less explored alternate teaching learning strategy can also prove a costeffective adjunct to mainstream strategies.

\section{Source of Funding}

This paper or work was not supported financially by any of the funding agency or individuals.

\section{Conflict of Interest}

The authors declare that there is no conflict of interest.

\section{References}

1. Pinilla S, Nicolai L, Gradel M, Pander T, Fischer MR, Borch P, et al. Undergraduate Medical Students Using Facebook as a Peer-Mentoring Platform: A Mixed-Methods Study. JMIR Med Educ. 2015;1(2):e12e12. doi: $10.2196 / m e d e d u .5063$.

2. Henning JM, Weidner TG, Marty MC. Peer Assisted Learning in Clinical Education: Literature Review. Athl Train Educ J. 2008;3(3):84-90. 101:-10/4085/94/-380x-3.3.84

3. Topping KJ. The effectiveness of peer tutoring in further and higher education: A typology and review of the literature. Higher Educ. 1996;32(3):321-45. 10i:10.1007bf00138870

4. Falchicov N, Blythman M. Learning Together. 1st ed. London: Routledge/Falmer; 2003.

5. Mathes E. Maslow's Hierarchy of Needs as a Guide for Living. $J$ Humanist Psychol. 1981;21(4):69-72.

6. O'Donnel A, King A. Cognitive Perspective on Peer Learning. 1st ed. Hoboken: Taylor and Francis; 2014.

7. Pittenger AL, LimBybliw AL. Peer-Led Team Learning in an Online Course on Controversial Medication Issues and the US Healthcare System. Am J Pharm Educ. 2013;77(7):150. doi:10.5688/ajpe777150.

8. Corneli J, Danoff CJ, Pierce C, Ricaurte P, Macdonald LS. Pub Dom Ed Press. 2016

9. Boud D, Boud D, Cohen R, Sampson J. Making the move to peer learning. Peer Learning in Higher Education: Learning from and with each other;

10. Sole G, Rose A, Bennett T, Jacques K, Rippon Z. A Student Experience of Peer Assisted Study Sessions in Physiotherapy. J Peer Learn. 2012;5:42-51.

11. Ladyshewsky R. Building Competency in the Novice Allied Health Professional through Peer Coaching. J Allied Health. 2010;39(2):7782.

12. Burgess A, McGregor D, Mellis C. Medical students as peer tutors: A systematic review. BMC Med Educ. 2014;14(1). 10.10. $186 / 472$ 6920-14-115

13. Topping K. Trends in Peer Learning. Educ Psychol. 2005;25(6):63145.

14. Christiansen A, Bell A. Peer learning partnerships: exploring the experience of pre-registration nursing students. J Clin Nurs. 2010;19(5-6):803-10. d01:10.1111/].1365-2702.2009.02981.x.

15. Glynn LG, MacFarlane A, Kelly M, Cantillon P, Murphy AW. Helping each other to learn - a process evaluation of peer assisted learning. BMC Med Educ. 2006;6(1). 10i:10.1186/742-6920-6-18.

16. Ray S, Ray M. Incorporation of peer learning in first MBBS curriculum to enhance metacognition skills. AJMS. 2012;5(4):33941.

17. Bennett D, O'Flynn S, Kelly M. Peer assisted learning in the clinical setting: an activity systems analysis. Adv Health Sci Educ. 2015;20(3):595-610. 101:0.1007/s [0459-0) 4-9557-x.

\section{Author biography}

Swati Paranjape, Assistant Professor

Madhavi Dharankar, Associate Professor and Head

Cite this article: Paranjape S, Dharankar M. Peer learning in health sciences-exploring pedagogy. J Educ Technol Health Sci 2021;8(1):12-15 